\title{
Two waves of pandemic influenza A(H1N1)2009 in Wales - the possible impact of media coverage on consultation rates, April - December 2009
}

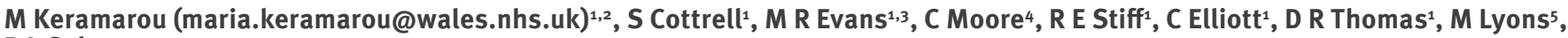 \\ R L Salmon ${ }^{1}$ \\ 1. Communicable Disease Surveillance Centre, Public Health Wales, Cardiff, United Kingdom \\ 2. European Programme on Intervention Epidemiology Training (EPIET) \\ 3. Department of Primary Care and Public Health, Cardiff University, United Kingdom \\ 4. Public Health Wales Microbiology, Cardiff, United Kingdom \\ 5. Health Protection Services, Public Health Wales, Cardiff, United Kingdom
}

Citation style for this article:

Keramarou M, Cottrell S, Evans MR, Moore C, Stiff RE, Elliott C, Thomas DR, Lyons M, Salmon RL. Two waves of pandemic influenza A(H1N1)20o9 in Wales - the possible impact of media coverage on consultation rates, April - December 2009. Euro Surveill. 2011;16(3):pii=19772. Available online: http://www. eurosurveillance.org/ViewArticle.aspx?Articleld $=19772$

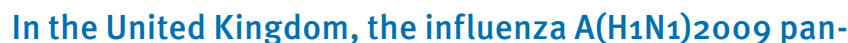
demic had a distinct two-wave pattern of general practice consultations for influenza-like illness (ILI). We describe the epidemiology of the influenza pandemic in Wales between April and December 2009 using integrated data from a number of independent sources: GP surveillance, community virology surveillance, hospital admissions and deaths, and media enquiries monitoring. The first wave peaked in late July at 100 consultations per 100,000 general practice population and attracted intensive media coverage. The positivity rate for the $\mathrm{A}\left(\mathrm{H}_{1} \mathrm{~N}_{1}\right)_{2009}$ influenza did not exceed $25 \%$ and only 44 hospitalisations and one death were recorded. By contrast, the second wave peaked in late October and although characterised by lower ILI consultation rates (65 consultations per 100,000 general practice population) and low profile media activity, was associated with much higher positivity rates for pandemic influenza $A\left(\mathrm{H}_{1} \mathrm{~N}_{1}\right)_{2} 2009(60 \%)$ and substantially more hospital admissions $(n=379)$ and deaths $(n=26)$. The large number of ILI-related consultations during the first wave in Wales probably reflected the intensive media activity rather than influenza virus circulating in the community. Data from community surveillance schemes may therefore have considerably overestimated the true incidence of influenza. This has implications for the future interpretation of ILI surveillance data and their use in policy making, and underlines the importance of using integrated epidemiological, virological and hospital surveillance data to monitor influenza activity.

\section{Introduction}

The media are major sources of health information. They can generate awareness of health issues and play key roles in health behaviour change [1]. Studies suggest that media reports are the main source of most parents' information about health problems [2]. The media can also influence the behaviour of healthcare professionals, for example by increasing awareness and reporting of communicable diseases especially during outbreaks $[3,4]$.

In mid-April 2009, a new strain of influenza $A\left(\mathrm{H}_{1} \mathrm{~N}_{1}\right)$ was identified in the United States (US). The same strain was identified in Mexico and Canada and later elsewhere. By late April the virus, then named novel influenza $\mathrm{A} / \mathrm{H}_{1} \mathrm{~N}_{1}$, had spread worldwide [5]. Within Europe, the United Kingdom (UK) and Spain were the countries initially most affected [6]. On 11 June 2009, after confirming community transmission of influenza $\mathrm{A}\left(\mathrm{H}_{1} \mathrm{~N}_{1}\right) 2009$ virus in two of its regions, the World Health Organization (WHO) declared an influenza pandemic [7].

On 29 May 2009, the first confirmed case of influenza $\mathrm{A}\left(\mathrm{H}_{1} \mathrm{~N}_{1}\right) 2009$ was diagnosed in Wales (a man returning from the US with a respiratory illness). In response, measures were taken in Wales to strengthen case finding and reporting of influenza-like illness (ILI) among travellers returning from affected areas [8]. All suspected cases were tested for the virus by specific realtime reverse transcription - polymerase chain reaction (RT-PCR) and confirmed by sequence analysis. All household contacts were given antiviral prophylaxis, oseltamivir, as part of an initial containment strategy.

On 6 July 2009, the Welsh Assembly Government announced a move from containment to mitigation after community transmission of influenza $A\left(\mathrm{H}_{1} \mathrm{~N}_{1}\right) 2009$ had been confirmed in several parts of Wales [9]. Active case finding and routine diagnostic testing for influenza were discontinued and tracing and prophylaxis of contacts ceased. All patients who were diagnosed clinically with influenza $A\left(\mathrm{H}_{1} \mathrm{~N}_{1}\right)_{2009}$ by a GP were given antiviral treatment and diagnostic laboratory testing was confined to suspected influenza cases admitted to hospital or presenting to a network of sentinel general 
practices. Thereafter, influenza activity in the general population was monitored using a variety of community surveillance systems.

In England, the National Pandemic Flu Service (NPFS) was introduced in mid-July 2009 in order to relieve pressure on primary care services [10]. Patients with influenza symptoms were advised not to consult their general practitioner (GP), but to contact the NPFS either online or by telephone in order to obtain antiviral drugs. This meant that GP surveillance data no longer provided a reliable indicator of influenza activity in England. However, in Wales, no change was made to usual arrangements for clinical influenza diagnosis and antiviral prescribing by GPs.

We investigated the impact of media coverage of the influenza pandemic in Wales between April and December 2009 on surveillance systems using integrated data from a number of independent sources.

\section{Methods}

We examined data on ILI consultation rates generated by NHS Direct Wales, two independent GP surveillance systems (GP sentinel surveillance of infection and rapid automated GP surveillance) in conjunction with laboratory data (community virology surveillance), hospital admissions and deaths in order to define the epidemic period of influenza and the distribution of other circulating viruses. We also analysed media interest in influenza $\mathrm{A}\left(\mathrm{H}_{1} \mathrm{~N}_{1}\right)_{2009}$ over the same time period. The data sources used are detailed below.

\section{NHS Direct Wales}

This is a nurse-led telephone helpline that provides health information and advice to callers. Anyone may call the helpline at any time and symptoms are classified based on a series of clinical algorithms. Call data can be used for syndromic surveillance and symptoms that correspond to the influenza/colds algorithm provide the basis for real-time, daily monitoring of ILI in the community [11].

\section{GP sentinel surveillance of infection}

Influenza activity is reported to Public Health Wales according to the GPs' clinical diagnosis of the patients' ILI symptoms (upper respiratory tract symptoms, fever, chills, myalgia and cough). The resulting data is reported on a weekly basis by 44 volunteer, sentinel general practices, approximately $9 \%$ of practices in Wales, covering some 356,000 people. Weekly clinical consultation rates are calculated per 100,000 general practice population by age group. The scheme has operated since 1985 with no change in case definition or reporting procedure, thus allowing historical comparisons to be made.

\section{Laboratory-based surveillance}

Virological surveillance was carried out to monitor the circulation of seasonal respiratory viruses. A volunteer subset of sentinel practices collected dry nasal/ throat swab samples from the first patients presenting with ILI symptoms each week (maximum five samples per week). These specimens were sent to the regional virus laboratory and tested for influenza A, influenza B, respiratory syncytial virus (RSV) and rhinovirus using real-time molecular techniques. All influenza A positive samples were subtyped as $\mathrm{A}\left(\mathrm{H}_{1} \mathrm{~N}_{1}\right)_{2} 2009$ or seasonal $\mathrm{H}_{1}$ or $\mathrm{H}_{3}$ viruses using real-time RT-PCR.

\section{Rapid automated GP surveillance}

Around 400 general practices across Wales (approximately $80 \%$ of practices in Wales) report clinical diagnoses of ILI, classified according to Read codes [12], on a daily basis using an automated computer system called Audit+ (Informatica Systems Ltd [13]. We used these data to calculate ILI consultation rates per 100,000 general practice population. Rates were calculated as rolling weekly rates based on the seven day period leading up to and including the report submission date. This scheme started in late April 2009 specifically to monitor the influenza pandemic in Wales.

Hospital admissions and deaths

All acute hospitals were asked to report admissions and deaths in hospital of people with laboratoryconfirmed influenza $A\left(\mathrm{H}_{1} \mathrm{~N}_{1}\right)$ 2009. GPs were asked to report any deaths from suspected influenza occurring outside hospital and post-mortem testing was carried out to confirm the diagnosis.

\section{Media coverage of pandemic influenza}

Google News captures articles from printed press, television, radio and internet sources. The keyword 'swine flu' was used to search Google News for media references between 1 January and 30 December 2009. Searches were conducted on a worldwide, UK, and Wales basis. A record of influenza-related media enquiries received by Public Health Wales was also maintained throughout the pandemic. These include only a fraction of media coverage of the influenza $A\left(\mathrm{H}_{1} \mathrm{~N}_{1}\right)_{2009}$ pandemic in Wales, but they tend to reflect levels of media coverage nationally.

\section{Results}

Surveillance of ILI-related calls to NHS Direct Wales

NHS Direct in Wales recorded a small peak in the percentage of calls related to influenza in early May 2009 about $25 \%$ of total calls), followed by a rapid rise to a peak of more than $50 \%$ of calls by mid-July. A second peak occurred in mid-October 2009 (30\% of calls). This level of influenza calls to NHS Direct Wales was higher than at any time during the previous four years (January 2006-December 2009), superseding the peak in December 2008 ( $28 \%$ of calls).

\section{Surveillance of ILI consultations} by the GP schemes

The GP sentinel surveillance scheme detected an increase in ILI consultations that exceeded the threshold for normal seasonal activity by mid-July 2009 
(week 29) (Figure 1). The first wave of ILI lasted from weeks 27 to 34 and reached a peak of nearly 100 consultations per 100,000 general practice population at the end of July (weeks 30-31). This was followed by a period of quiescence during August before the development of a second wave of ILI in the autumn, which started in early September (week 38), peaked in late October (week 42) and receded at the end of December (week 52). The second wave was more prolonged than the first, with a lower peak in consultation rate of 65 consultations per 100,000 general practice population. Neither of the waves exceeded an ILI rate of 100 consultations per 100,000 general practice population, the threshold used by the scheme for higher than average seasonal activity. During both waves, rates were recorded well below those in winter 1999/2000, the last winter season when substantial influenza activity occurred in Wales.

ILI consultation rates by sex were similar for both waves with females accounting for $58 \%$ of consultations in the first wave and $56 \%$ in the second. The mean age for ILI consultations was 32.1 years (standard deviation 19.9 years) and $75 \%$ of consultations were in people under 45 years of age. There was a difference in the age distribution of patients consulting with ILI during the two waves (Figure 2). In the first wave, consultation rates were highest in children aged 0-4 years and lowest in the 5-19 age group, while in the second wave rates were highest in the 10-14 age group.
Virological surveillance of GP sentinel samples The two waves of ILI activity also differed with respect to a number of other epidemiological characteristics. Both the number of people being tested and the proportion testing positive for influenza $A\left(\mathrm{H}_{1} \mathrm{~N}_{1}\right)_{2} 2009$ were much higher during the second wave than the first (Figure 3). The proportion testing positive remained below $25 \%$ during the first wave, but reached almost $60 \%$ at the peak of the second wave (week 43). Neither of the two waves was associated with substantial numbers of positive tests for other respiratory viruses, and the influenza $A\left(\mathrm{H}_{1} \mathrm{~N}_{1}\right)_{2009}$ virus was the only influenza strain identified. During the first wave, samples were as likely to test positive for rhinovirus as influenza $\mathrm{A}\left(\mathrm{H}_{1} \mathrm{~N}_{1}\right)$ 2009. However, from early October (week 40) the majority of positive tests were for influenza $A\left(H_{1} N_{1}\right) 2009$, until late November (week 48) when RSV became the dominant virus identified (Figure 3 ).

Surveillance of hospitalisations and deaths During the first wave, there were 44 hospital admissions and one patient died from confirmed influenza $A\left(H_{1} N_{1}\right) 2009$. By contrast, the second wave resulted in substantially more hospital admissions $(n=379)$, despite lower ILI consultation rates in GP, including over 60 admissions to intensive care units and 26 deaths (Figure 4).

Surveillance of media reports and enquires The Google News search for news articles showed that the highest concentration of media reports on

\section{FIGURE 1}

Weekly consultation rates for influenza-like illness per 100,000 general practice population in Wales, United Kingdom, $1999 / 2000$ and 2007/08-2009/10a

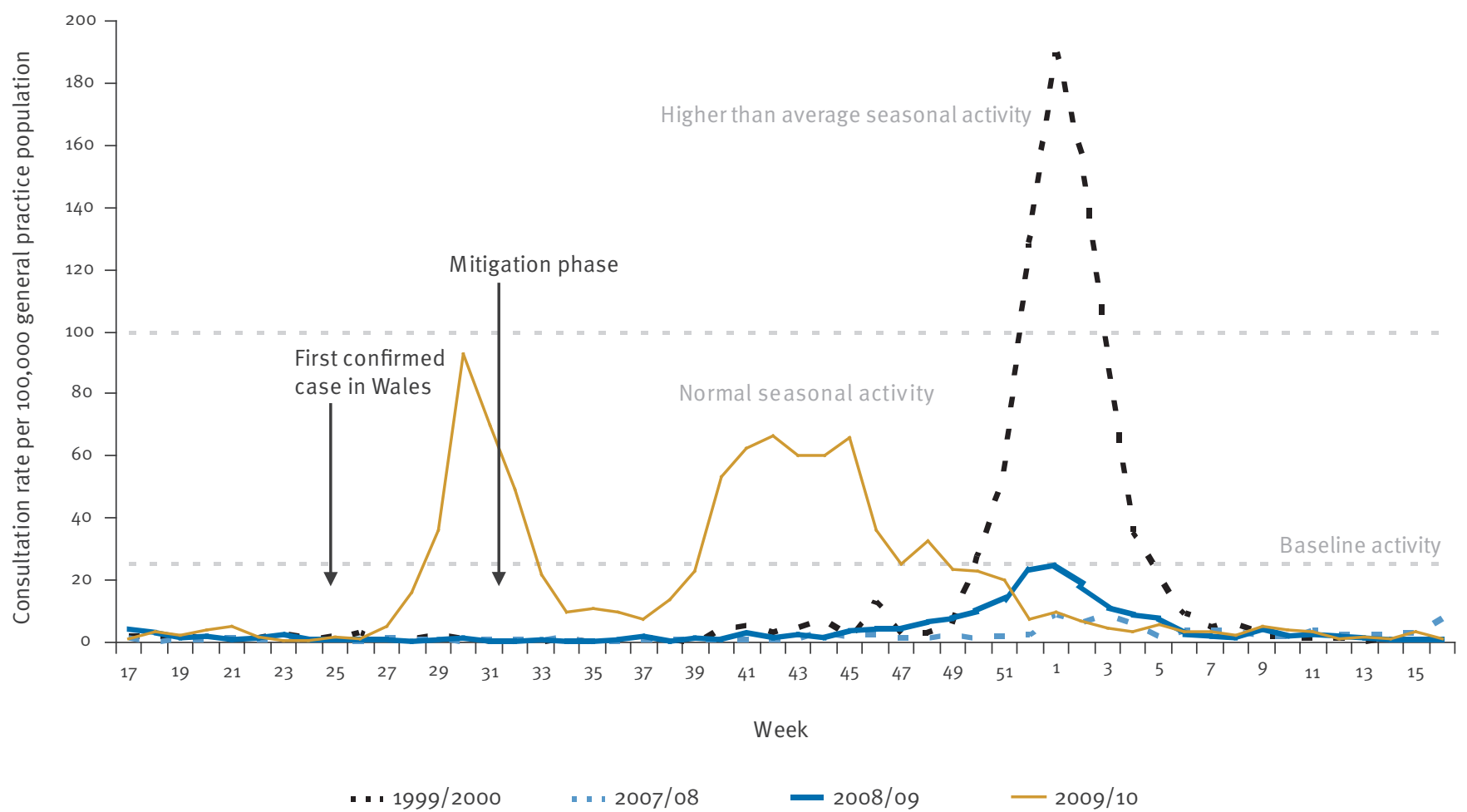

a Key events in 2009/10 are shown on the graph.

Source: Public Health Wales (general practitioner sentinel surveillance scheme). 
pandemic influenza occurred during May 2009 with 34,300 reports internationally and 2,560 in the UK. The second highest month for articles in the UK was July 2009 with 2,330 reports.

Public Health Wales received 344 influenza-related media enquiries between April and December 2009. Of these, 172 came from print media, 92 from radio, 76 from television, and four from other sources. The highest peak in media coverage was recorded in week

\section{FIGURE 2}

Consultation rates by age group during the first and the second pandemic influenza A(H1N1)2009 wave, Wales, United Kingdom, weeks 27-52, 2009

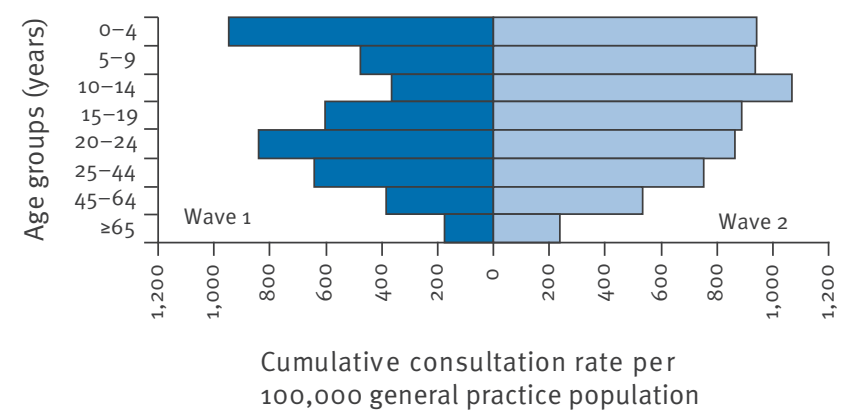

18 when WHO raised the level of influenza pandemic alert to phase 4 and later to phase 5 (Figure 5). Media interest dropped considerably after this week. Another wave of media interest began in week 26 , preceding the first wave. A third period of media activity occurred at the end of October and beginning of November, coinciding with the launch of influenza $A\left(\mathrm{H}_{1} \mathrm{~N}_{1}\right)_{2009}$ vaccine in the UK.

\section{Discussion}

The influenza $A\left(\mathrm{H}_{1} \mathrm{~N}_{1}\right)_{2009}$ pandemic in Wales was characterised by two waves in ILI consultation rates that peaked in late July and late October 2009 respectively. However, the two waves were strikingly different in their epidemiological features. During the first wave, the highest ILI rates were in preschool children and the lowest rates in school children. During the second wave, the highest ILI rates were in school children. The first wave was also characterised by a much lower proportion of confirmed infections, and far fewer hospital admissions and deaths. These findings led us to question whether the first wave of ILI consultations in Wales was a genuine reflection of large numbers of infected people or mainly a consequence of extensive media coverage. A number of possible explanations for the differences observed between the two waves are considered below.

Source: Public Health Wales (Rapid general practitioner surveillance of influenza using Audit+).

\section{FIGURE 3}

Community virological surveillance showing tests for respiratory viruses and proportion positive for influenza A(H1N1)2009, Wales, United Kingdom, weeks 27-52 a 2009

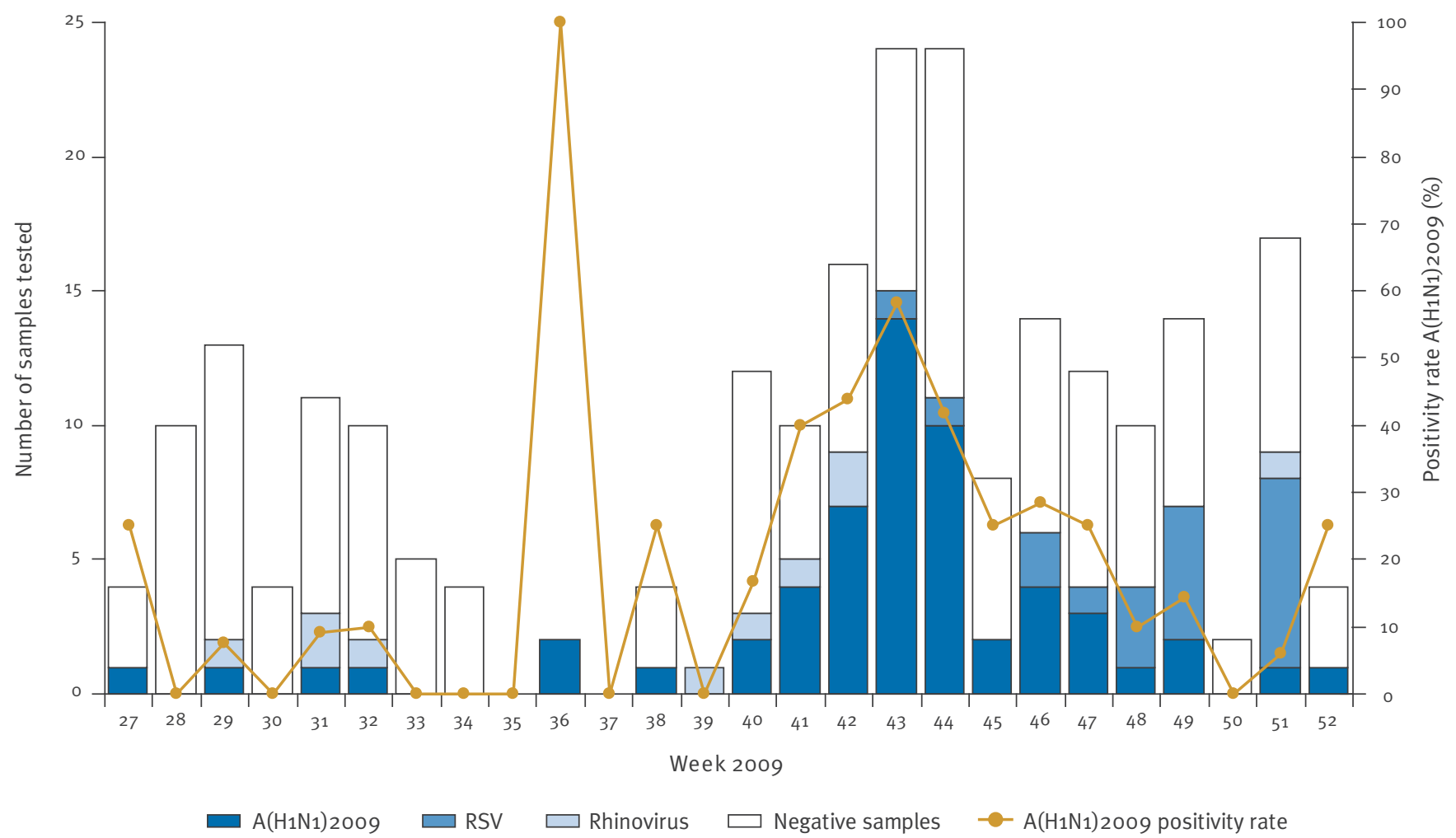

RSV: respiratory syncytial virus.

a In week 36 only two samples were tested, both were positive.

Source: Public Health Wales (regional virus laboratory). 
Firstly, there may have been a lower threshold for contacting NHS Direct or consulting a GP during the first wave. This may have been influenced by extensive media coverage early in the pandemic, also observed in other countries $[14,15]$, and perhaps by general public anxiety and fear of the unknown. Additionally, the public health message delivered by the public health authorities to consult promptly in order to obtain

\section{FIGURE 4}

Consultation rates for influenza-like illness, and admissions to hospital and deaths from influenza A(H1N1)2009, Wales, United Kingdom, weeks 18-52, 2009

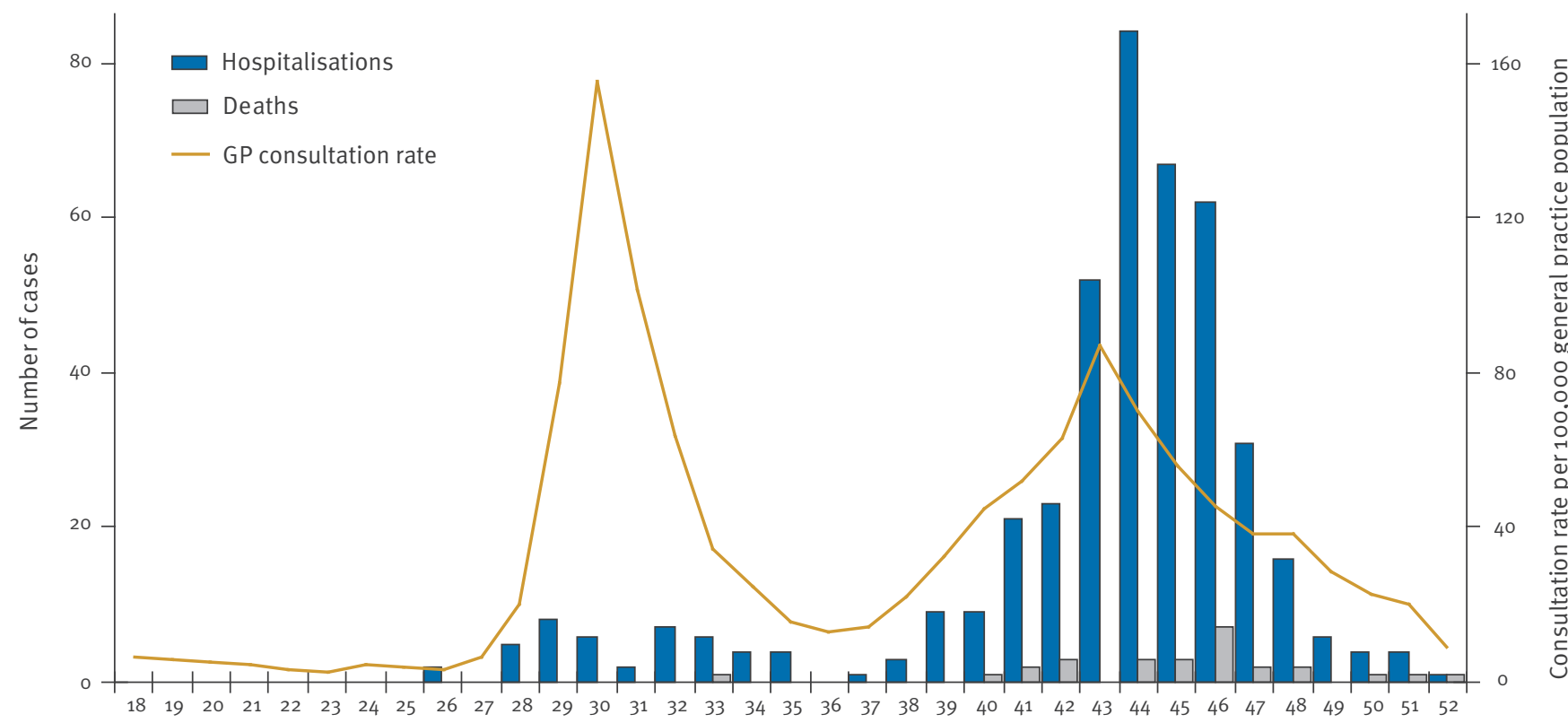

Week 2009

Source: Public Health Wales (Health Protection Services and Audit+).

\section{FIGURE 5}

Media enquiries about influenza A(H1N1)2009 received by Public Health Wales, April - December 2009

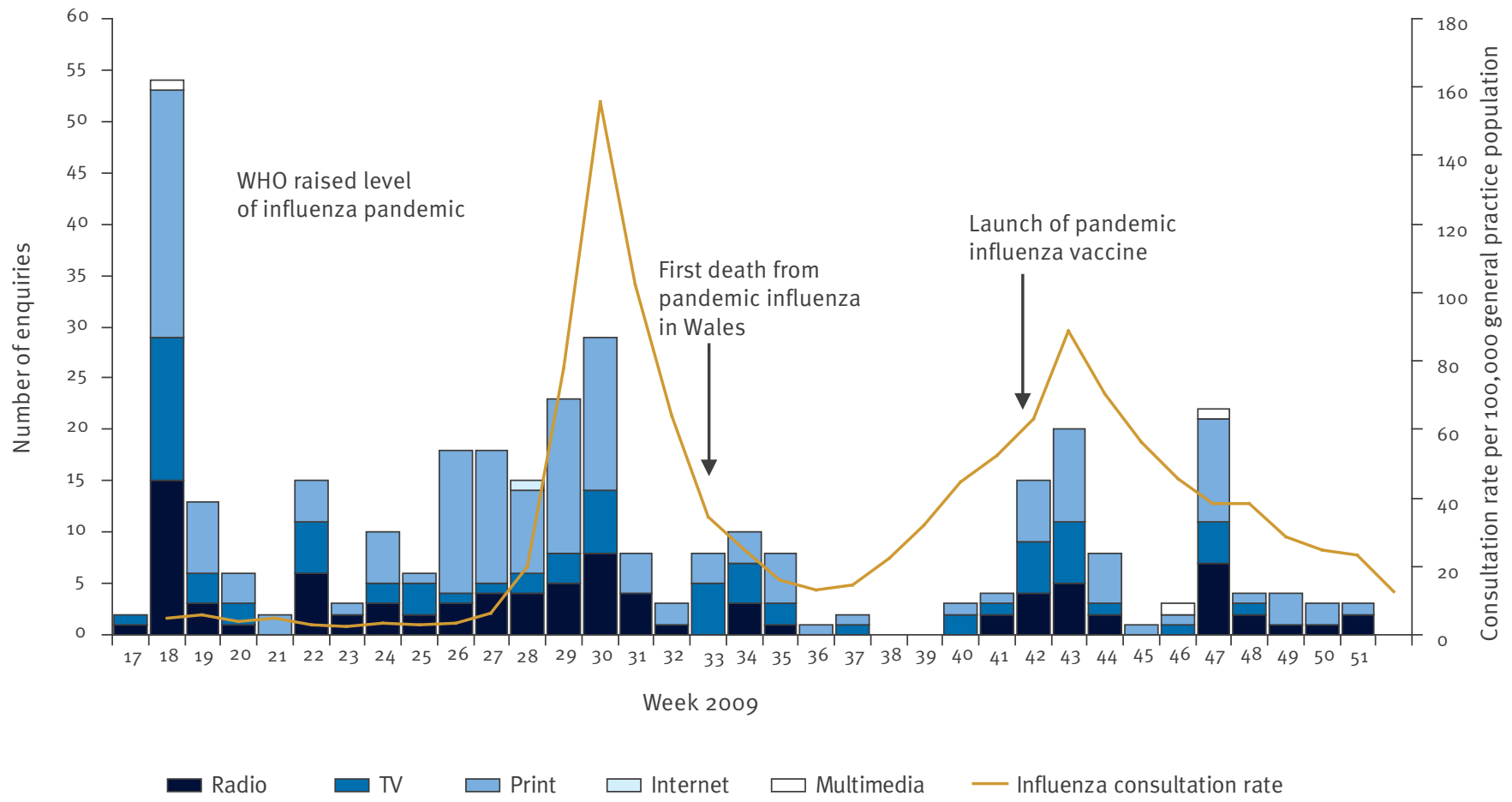

TV: television; WHO: World Health Organization.

Source: Public Health Wales (Communications team and Audit+). 
medical advice and treatment with antiviral medication may have led patients with minor upper respiratory infections, who would not normally consult, to seek medical care [16]. This would account for the low positivity rate for influenza $\mathrm{A}\left(\mathrm{H}_{1} \mathrm{~N}_{1}\right) 2009$ in community samples in the first wave.

Secondly, GPs may have had been more likely than usual to suspect influenza in patients presenting with non-specific respiratory symptoms, particularly since public health authorities encouraged a low diagnostic threshold as part of the case-finding approach used during the initial stages of the pandemic Moreover, GPs may have also been influenced by the extensive media coverage. As a result they may have obtained samples from patients with mild respiratory symptoms, accounting for the low proportion of positive tests.

Thirdly, the difference between the two waves may be an artefact of surveillance. However, unlike in England where the introduction of the NPFS substantially altered the pattern of GP consultation (and hence make it difficult to interpret GP sentinel surveillance data), no such changes were made in Wales. New diagnostic codes were introduced for influenza $A\left(\mathrm{H}_{1} \mathrm{~N}_{1}\right) 2009$ by some GP software providers but similar patterns in ILI rates were recorded by both GP surveillance systems in Wales even though they operate independently and used different methods: one based on a weekly return of cases meeting a clinical case definition and the other based on automated extraction of coded diagnoses from general practice computers. Triangulation of data from both GP surveillance schemes and from NHS Direct Wales shows synchronous timing in the peaks, indicating that the three data sources were recognising the same phenomenon.

Fourthly, there may have been other respiratory viruses giving rise to ILI symptoms circulating at the time of the first wave. Some virological specimens were positive for other viruses, particularly rhinovirus which accounted for half of the samples testing positive during the first wave. It is possible that viral interference could have affected the spread of influenza $A\left(\mathrm{H}_{1} \mathrm{~N}_{1}\right)_{2009}$ virus during the first wave in Wales, as occurred elsewhere in the autumn $[17,18]$. However, this rhinovirus activity is more likely to represent background levels rather than a coincident epidemic, though there are no historical Welsh data from the summer months available for comparison as community samples are normally only tested during the influenza season. During the second wave, influenza $\mathrm{A}\left(\mathrm{H}_{1} \mathrm{~N}_{1}\right)_{2009}$ was the predominant virus identified until the onset of the RSV season in late November.

Fifthly, influenza $A\left(\mathrm{H}_{1} \mathrm{~N}_{1}\right)_{2} 009$ may have been underestimated during the first wave because of false negative laboratory tests. The reliability of virological testing depends on the timing of the sample (negative tests are more likely five or more days after symptom onset), the quality of the sample, and the sensitivity and specificity of the test [19]. Sample quality might be affected if primary care staff improved their sampling technique as the pandemic progressed. However, sample quality is routinely checked by the laboratory using a housekeeping gene probe to confirm the presence of human RNA and there was no change in the proportion of samples with inadequate cells. This explanation is therefore unlikely.

Finally, the much higher number of hospital admissions and deaths of people with confirmed influenza during the second wave might be due to a change in the virulence of the virus or to a change in hospital testing policy. There is no evidence for increased virulence of the influenza $A\left(\mathrm{H}_{1} \mathrm{~N}_{1}\right)_{2} 2009$ virus during the second wave and hospital testing policy remained consistent throughout the pandemic. The simplest explanation is that there were higher levels of influenza $\mathrm{A}\left(\mathrm{H}_{1} \mathrm{~N}_{1}\right)_{2} 2009$ circulating in the community during the second wave in Wales, as demonstrated by the much higher influenza positivity rate in community samples.

There are several strengths as well as limitations to our study. We used a number of independent data sources to analyse the two waves of influenza $A\left(\mathrm{H}_{1} \mathrm{~N}_{1}\right)_{2} 009$ in Wales, and all reflect the same phenomenon. Health service arrangements for clinical diagnosis and treatment of influenza remained consistent in contrast to England where the NPFS was introduced partway through the pandemic. Virological surveillance was also carried out consistently throughout the pandemic with participating practices instructed to send a maximum of five specimens per week from patients meeting the ILI case definition.

The main limitation of the study is the absence of detailed information on the symptoms of the patients consulting with ILI. The GP surveillance schemes rely either on an imprecise clinical case definition of ILI or automated extraction of relevant Read codes, neither of which capture subtle changes in presenting symptoms. Virological surveillance was restricted to five viruses, (influenza $A$, influenza $B$, influenza $A\left(\mathrm{H}_{1} \mathrm{~N}_{1}\right) 2009$, RSV and rhinovirus), so we cannot tell if some ILI consultations were due to other respiratory viruses, such as parainfluenza virus or adenovirus.

In conclusion, Wales experienced two waves of pandemic influenza during mid-summer and mid-autumn 2009 respectively. Each wave presented a different epidemiological profile. The first wave had a lower proportion of ILI cases confirmed as influenza and fewer hospital admissions and deaths compared with the second. These differences are most likely to be due to the different thresholds for contacting a GP that existed during the period of the pandemic and the different risk perceptions of the population over time. This was probably triggered by changes in media coverage throughout the pandemic and especially the high media profile during the initial stages of the pandemic, causing public anxiety. What is clear is 
that most patients presenting with ILI during the first wave in Wales do not appear to have had influenza and therefore did not require antiviral treatment. This has implications for the interpretation of surveillance data on ILI and on its use in policymaking. Above all, our study underlines the importance of using integrated epidemiological, virological and hospital surveillance data to routinely monitor influenza activity.

\section{Acknowledgements}

We thank Olesya Mustafa and the general practitioners who participate in the sentinel surveillance scheme, Public Health Wales (PHW) health protection services for data on hospitalisations and deaths, Chris Lines, PHW communications team for data on media enquiries, and Gwyneth Thomas, Welsh Assembly Government for providing data on calls to NHS Direct Wales. We are also grateful to Simon Scourfield and Joe Hunt from the Primary Care Informatics Programme, Informing Healthcare, GPC Wales and all the practices who participate in the Audit+ scheme.

\section{References}

1. Stryker JE. Media and marijuana: A longitudinal analysis of news media effects on adolescents' marijuana use and related outcomes, 1977-1999. J Health Commun. 2003;8(4):305-28

2. Danovara-Joliday MC, Wood AL, LeBaron CW, Rotavirus vaccine and the news media, 1987-2001. JAMA. 2002;287(11);1455-62

3. Olowokure B, Clark L, Elliot AJ, Harding D, Fleming A, Mumps and the media: changes in the reporting of mumps in response to newspaper coverage. J Epidemiol Community Health. 2007;61(5):385-8

4. Davis JP, Vergeront JM. The effect of publicity on the reporting of toxic-shock syndrome in Wisconsin. J Infect Dis. 1982;145(4):449-57

5. Novel Swine-Origin Influenza $A\left(\mathrm{H}_{1} \mathrm{~N}_{1}\right)$ Virus Investigation Team. Emergence of a novel swine-origin influenza $A\left(\mathrm{H}_{1} \mathrm{~N}_{1}\right)$ virus in humans. N Engl J Med. 2009;360(25):2605-15

6. World Health Organization (WHO). Swine influenza - update 4. 28 April 2009. Available from: http://www.who.int/csr/ don/2009_04_28/en/index.html

7. World Health Organization (WHO). Influenza $A\left(\mathrm{H}_{1} \mathrm{~N}_{1}\right)$ : WHO announces pandemic alert phase 6 of moderate severity. Copenhagen: WHO, 2009. Available from: http://www.euro. who.int/en/what-we-publish/information-for-the-media/ sections/press-releases/2009/06/influenza-a-h1n1-whoannounces-pandemic-alert-phase-6,-of-moderate-severity

8. Health Protection Agency, Health Protection Scotland, National Public Health Service for Wales, HPA Northern Ireland Swine influenza investigation teams. Epidemiology of new influenza A $\left(\mathrm{H}_{1} \mathrm{~N}_{1}\right)$ virus infection, United Kingdom, April - June 2009. Euro Surveill. 2009;14(22):pii=19232. Available from:http://www. eurosurveillance.org/ViewArticle.aspx?Articleld=19232

9. Welsh Assembly Government. Department for Public Health and Health Professions. Chief Medical Officer. Influenza. $\mathrm{A}\left(\mathrm{H}_{1} \mathrm{~N}_{1}\right)$ - next steps [letter]. CMO(2009)6. Cardiff:.2009. Available from: http://wales.gov.uk/docs/phhs/publications/ cmoletter200906/090707cmolettero6en.doc

10. Department of Health. Launch of the National Pandemic Flu Service. July, 2009. Available from: http://www.dh.gov.uk/en/ Publichealth/Flu/Swineflu/DH_102909

11. Smith GE, Cooper DL, Loveridge P, Chinemana F, Gerard E, Verlander N. A national syndromic surveillance system for England and Wales using calls to a telephone helpline. Euro Surveill. 2006;11(12):pii=667. Available from: http://www. eurosurveillance.org/ViewArticle.aspx?Articleld=667

12. Chisholm J. The Read clinical classification. BMJ. 1990;300(6732):1092.

13. Informatica Systems Ltd. Audit+. Available from: http:// www.informatica-systems.co.uk/pages/viewpage. action?pageld $=2162725$

14. Duncan B. How the media reported the first days of the pandemic $\left(\mathrm{H}_{1} \mathrm{~N}_{1}\right)$ 2009: results of EU-wide media analysis. Euro Surveill. 2009;14(30):pii=19286. Available from:http://www. eurosurveillance.org/ViewArticle.aspx?Articleld=19286
15. Thouillot F, Do C, Balleydier E, Rachou E, Staikowsky F, Morbidelli $P$, et al. Preliminary analysis of the pandemic $\mathrm{H}_{1} \mathrm{~N}_{1}$ influenza on Reunion Island (Indian Ocean): surveillance trends (July to Mid-September 2009). Euro Surveill. 2009;14(42):pii=19364. Available from : http://www. eurosurveillance.org/ViewArticle.aspx?Articleld=19364

16. Turbelin C, Pelat C, Boelle PY, Levy-Bruhl D, Carrat F, Blanchon $\mathrm{T}$, et al. Early estimates of 2009 pandemic influenza $A\left(\mathrm{H}_{1} \mathrm{~N}_{1}\right)$ virus activity in general practice in France: incidence of influenza-like illness and age distribution of reported cases. Euro Surveill. 2009;14(39):pii=19341. Available from: http:// www.eurosurveillance.org/ViewArticle.aspx?Articleld=19341

17. Linde A, Rotzen-Ostlund M, Zweygberg-Wirgart B, Rubinova S Brytting $M$. Does viral interference affect spread of influenza? Euro Surveill 2009;14(40):pii=19354. Available from: http:// www.eurosurveillance.org/ViewArticle.aspx?Articleld=19354

18. Casalegno JS, Ottmann M, Duchamp MB, Escuret V, Billaud $\mathrm{G}$, Frobert E, et al. Rhinoviruses delayed the circulation of the pandemic influenza $A\left(\mathrm{H}_{1} \mathrm{~N}_{1}\right) 2009$ virus in France. Clin Microbiol Infect. 2010;16(4):326-9.

19. Wallace LA, Collins TC, Douglas JD, McIntyre S, Millar J, Carman WF. Virological surveillance of influenza-like illness in the community using PCR and serology. J Clin Virol. 2003;32(1):40-5. 